\title{
Equações de Predição das Exigências Protéicas para Frangos de Corte ${ }^{1}$

\author{
Flavio Alves Longo², Nilva Kazue Sakomura ${ }^{3}$, Adriana Nogueira Figueiredo², \\ Carlos Bôa-Viagem Rabello², Antônio Sergio Ferraudo 4
}

\begin{abstract}
RESUMO - O objetivo do trabalho foi determinar equações de predição das exigências de proteína bruta (PB) para frangos de corte machos e fêmeas através do método fatorial. Na determinação das exigências de proteína bruta para mantença, foi utilizada a técnica do balanço de nitrogênio. As exigências de proteína bruta para o crescimento foram determinadas em função do conteúdo de nitrogênio na carcaça e a eficiência de utilização do nitrogênio da dieta. A partir dos valores das exigências para mantença e para crescimento foram elaboradas equações de predição para as exigências diárias de $\mathrm{PB}$ (g/ave/ dia) para frangos de corte machos $(7 \mathrm{a} 21 \mathrm{dias}-\mathrm{PB}=1,323 \mathrm{xP} 0,75$ $+0,256 \mathrm{xG}, 22$ a 42 dias $-\mathrm{PB}=1,323 \mathrm{xP}^{0,75}+0,277 \mathrm{xG}$ e 43 a 56 dias $\left.-\mathrm{PB}=1,323 \mathrm{xP}^{0,75}+0,283 \mathrm{xG}\right)$ e fêmeas $\left(7\right.$ a 21 dias $-\mathrm{PB}=1,748 \mathrm{x} \mathrm{P}^{0,75}$ $+0,258 \mathrm{xG}, 22$ a 42 dias $-\mathrm{PB}=1,748 \mathrm{xP}^{0,75}+0,274 \mathrm{xG}$, e 43 a 56 dias - $\left.\mathrm{PB}=1,748 \times \mathrm{P}^{0,75}+0,300 \mathrm{xG}\right)$, em que $\mathrm{P}=$ peso corporal (kg) e $\mathrm{G}=$ ganho de peso diário ( $\mathrm{g} / \mathrm{dia}$ ). Recomenda-se a utilização das equações para a determinação das exigências mínimas de nitrogênio ou proteína bruta somente com atenção no atendimento das exigências em aminoácidos.
\end{abstract}

Palavras-chave: equações de predição, exigências de proteína bruta, frangos de corte, ganho de peso, mantença, método fatorial

\section{Prediction Equations for Protein Requirements on Broilers}

\begin{abstract}
The objective of this study was to determine prediction equations for crude protein (CP) requirements for males and females broilers using the factorial method. In order to determine the crude protein for the maintenance was used the nitrogen balance technique. The crude protein requirements for weight gain were determined based on body nitrogen content and nitrogen utilization efficiency for the diet. Considering the requirements for maintenance and weight gain were elaborated prediction equations for $\mathrm{CP}$ requirements ( $\mathrm{g} / \mathrm{bird} / \mathrm{day}$ ) for males broilers ( 7 to 21 days $-\mathrm{PB}=1.323 \mathrm{xW}^{0.75}+0.256 \mathrm{xG}, 22$ to 42 days $-\mathrm{PB}=1.323 \times \mathrm{W}^{0.75}+0.277 \mathrm{xG}$, and 43 to 56 days $\left.-\mathrm{PB}=1.323 \mathrm{xW}^{0.75}+0.283 \mathrm{xG}\right)$ and females $\left(7\right.$ to 21 days $-\mathrm{PB}=1.748 \mathrm{xW}^{0.75}+0.258 \mathrm{xG}, 22$ to 42 days $-\mathrm{PB}=$ $1.748 \times \mathrm{W}^{0.75}+0.274 \times \mathrm{x}$, and 43 a 56 days $\left.-\mathrm{PB}=1.748 \mathrm{xW}^{0.75}+0.300 \mathrm{xG}\right)$ where $\mathrm{W}=$ body weight $(\mathrm{kg})$ and $\mathrm{G}=$ daily weight gain ( $\mathrm{g}$ /day). The prediction equations utilization is recommended to determine the minimal nitrogen or crude protein requirements considering the amino acid requirements.
\end{abstract}

Key Words: broilers, crude protein requirements, factorial method, maintenance, weight gain

\section{Introdução}

Na avicultura as exigências nutricionais são constantemente reavaliadas para permitir a otimização dos nutrientes das dietas, uma vez que a nutrição e alimentação das aves varia muito em função da diminuição nos custos de produção ou pelas constantes variações genéticas em busca de melhores desempenhos e maior competitividade.

O fornecimento adequado de proteína para aves em crescimento tem o objetivo de dar condições às aves expressarem o máximo desenvolvimento corporal, com formação de massa muscular e empenamento. Por outro lado, o fornecimento inadequado de proteína provocará redução no crescimento da ave, como resultado de provável desvio de proteína de funções menos vitais para manter as funções mais vitais, prejudicando assim o desenvolvimento corporal (NATIONAL RESERCH COUNCIL - NRC, 1994).

A proteína é fundamental para o metabolismo das aves, pois está relacionada a processos vitais do organismo. Sabe-se que as exigências de proteína variam consideravelmente de acordo com a taxa de crescimento. Os aminoácidos contidos na proteína da dieta são utilizados pelas aves como constituintes estruturais primários de tecidos, como pele, penas, matriz óssea, ligamentos, bem como órgãos e músculos, além de contribuírem para diversas funções metabólicas e serem percursores de constituintes corporais não-protéicos (NRC, 1994).

\footnotetext{
1 Trabalho vinculado a Projeto Temático financiado pela FAPESP.

2 Zootecnistas - Estudantes de Pós Graduação - FCAV - UNESP - Jaboticabal. E.mail: falongo@yahoo.com

3 Prof. Dep. de Zootecnia - FCAV - UNESP - Jaboticabal, autor para correspondência. E.mail: sakomura@fcav.unesp.br

4 Prof. Departamento de Ciências Exatas - FCAV - UNESP - Jaboticabal.
} 
Os fatores principais que contribuem para as diferentes exigências mínimas de aminoácidos essenciais e nitrogênio não essencial são o peso da ave e o consumo de ração. SANTOMÁ (1991) salienta que a maior dificuldade de estabelecer as exigências nutricionais precisamente deve-se a uma interação entre proteína, energia, ambiente e marca comercial.

A forma mais precisa de estabelecer as exigências de proteína se baseia no método fatorial, o qual consiste em determinar as necessidades de proteína considerando a soma das necessidades para mantença e crescimento (HURWITZ et al., 1978). O método fatorial constitui ainda a base para a estimativa das necessidades de proteína através de modelos matemáticos que levam em consideração a ingestão, eficiência de deposição do nutriente e o peso vivo da ave (SANTOMÁ, 1991).

Do ponto de vista fisiológico o melhor critério para o estabelecimento da exigência de proteína é a medida da taxa de deposição protéica (SANTOMÁ, 1991). A deposição de proteína pode ser estimada através da retenção de nitrogênio, a qual pode ser determinada pela técnica de abate comparativo e a exigência de nitrogênio para mantença pela técnica do balanço de nitrogênio (SAKOMURA, 1996).

A mantença é definida como a situação em que a ave está em equilíbrio de nitrogênio, ou seja, a quantidade de nitrogênio ingerida deverá ser igual a quantidade de nitrogênio excretada. Desta forma a exigência de nitrogênio para mantença, pode ser estimada como sendo a quantidade de nitrogênio ingerida necessária para manter a ave em equilíbrio de nitrogênio (SCOTT et al., 1982).

As exigências de nitrogênio ou proteína para o crescimento são escassas na literatura. BASAGLIA et al. (1998) e SILVA (1999), utilizando a técnica do abate comparativo, determinaram as exigências de nitrogênio para ganho de peso como sendo o coeficiente de regressão do conteúdo de nitrogênio corporal total em função do peso corporal.

As pesquisas para determinação das exigências de proteína para aves em crescimento são limitadas, dando-se maior enfoque a testes de níveis de proteína nas dietas, os quais são bastante variados. $\mathrm{Na}$ prática as recomendações de proteína para as aves são geralmente especificadas em porcentagem da dieta, as quais para frangos de corte variam de 23 a $16 \%$, em função da fase de criação (LEESON e SUMMERS, 1997).

Os objetivos do presente estudo foram determinar por meio do método fatorial, as exigências de proteína para mantença e crescimento de frangos de corte machos e fêmeas, bem como estabelecer equações de predição das exigências de proteína e verificar suas aplicações através de simulações matemáticas.

\section{Material e Métodos}

Vários ensaios foram realizados no Aviário Experimental do Departamento de Zootecnia da Faculdade de Ciências Agrárias e Veterinárias - UNESP - Jaboticabal com a finalidade de elaborar a equação de predição das exigências protéicas para frangos de corte.

Determinação das exigências protéicas para mantença

Para determinar as exigências de proteína para mantença, foi utilizada a técnica do balanço de nitrogênio. Foi conduzido um ensaio de metabolismo com duração de oito dias, sendo quatro dias para adaptação às dietas experimentais e quatro dias para quantificação da ingestão de alimento e coleta total de excretas. Sessenta e quatro frangos de corte machos e fêmeas da marca comercial Ross com 49 dias de idade foram mantidos em gaiolas à temperatura ambiente. As aves foram distribuídas inteiramente ao acaso em quatro tratamentos, com quatro repetições de duas aves por tratamento para cada sexo. Os tratamentos consistiram no fornecimento de quatro dietas isocalóricas com níveis decrescentes de proteína bruta $(16,10,6$ e 3\%). Os níveis de proteína tiveram a finalidade de proporcionar balanços positivo, próximo a zero e negativo. Foram utilizados ingredientes com reduzido teor protéico, como farinha de mandioca $(1,7 \%$ de $\mathrm{PB})$ e a fécula de mandioca $(0,05 \%$ de PB), para formulação das dietas com menores níveis de proteína. O alimento e água foram fornecidos à vontade.

$\mathrm{Na}$ Tabela 1 são apresentadas as composições e os níveis nutricionais das dietas experimentais.

A partir da quantificação da ração ingerida, das excretas produzidas durante o período de ensaio de metabolismo e dos teores de nitrogênio das amostras de ração e excretas, calculou-se os valores diários de ingestão, excreção e balanço de nitrogênio.

Por meio da regressão linear do balanço de nitrogênio em função do nitrogênio ingerido foi determinada a exigência de nitrogênio para mantença como sendo o nitrogênio ingerido quando a retenção deste 
Tabela 1 - Dietas experimentais

Table 1 - Experimental diets

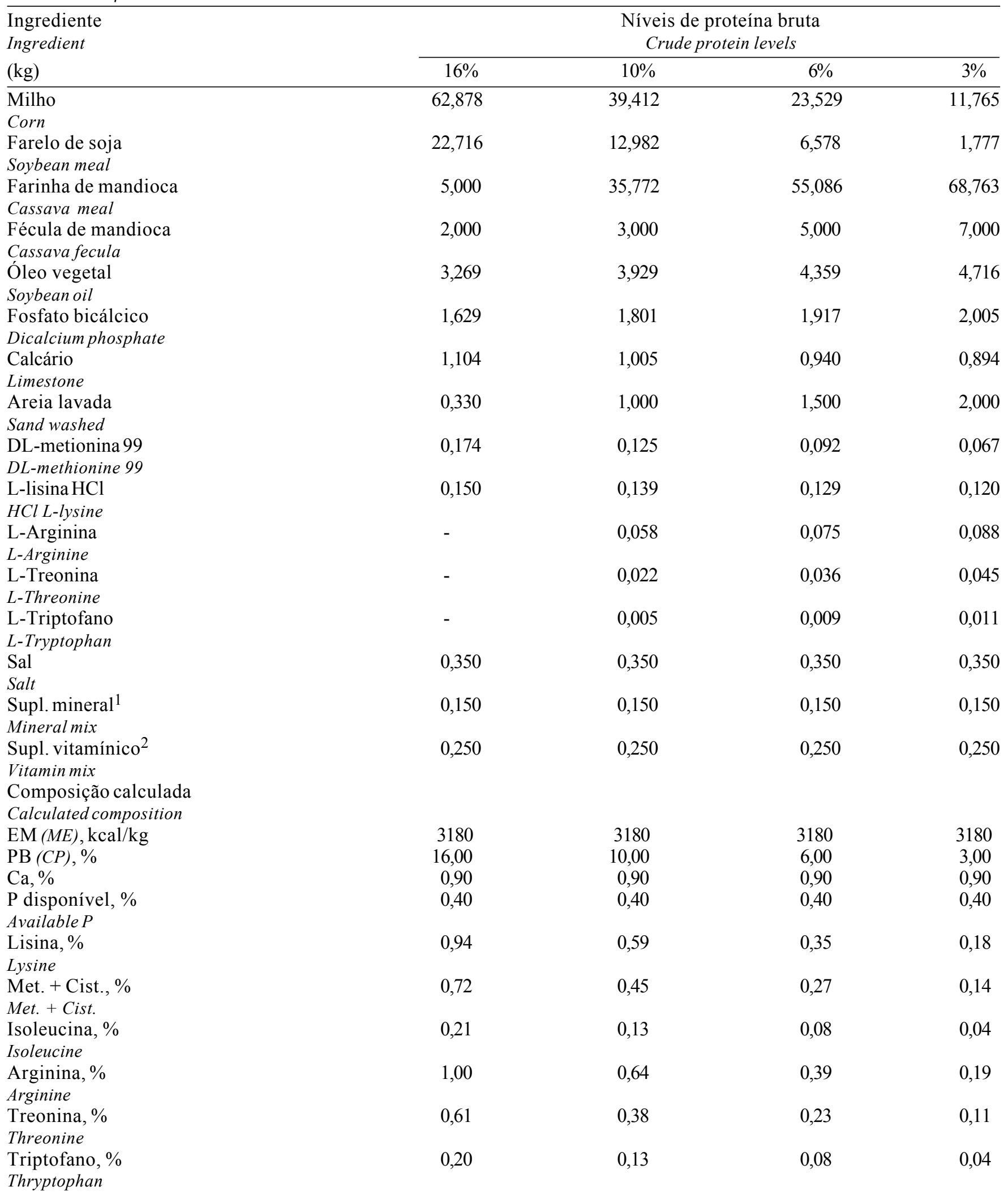

${ }^{1}$ Suplemento mineral, por quilograma do produto (Mineral mix, each kg contained): Fe, 35000 mg; Cu, 50000 mg; Mn, 35000 mg; Zn, 30000 mg; l, 600 $\mathrm{mg}$; Se, $90 \mathrm{mg}$.

2 Suplemento Vitamínico, por quilograma do produto (Vitamin mix, each $\mathrm{kg}$ contained) : vit. A, $2500000 \mathrm{UI}$; vit. $\mathrm{D}_{3}, 520000 \mathrm{UI}$; vit. E, $3200 \mathrm{mg}$; vit. $\mathrm{K}_{3}, 320$ mg; vit. $B_{1}, 100$ mg; vit. $B_{2}, 800$ mg; vit. $B_{12}, 4000$ mcg; ácido pantotênico (pantothenic acid), 1300 mg; ácido nicotínico (nicotinic acid), 5000 mg; metionina (methionine), $200 \mathrm{~g}$; colina (choline), $140 \mathrm{~g} ; \mathrm{BHT}, 20 \mathrm{~g}$. 
nutriente é igual a zero e, as perdas endógenas e metabólicas como sendo o valor do balanço de nitrogênio quando a ingestão de nitrogênio é nula (BURNHAM e GOUS, 1992).

Determinação das exigências protéicas para o ganho de peso

Para determinação das exigências de proteína bruta para ganho de peso foi conduzido um ensaio em temperatura ambiente. 180 machos e 180 fêmeas de frango de corte de um dia de idade foram distribuídos em oito grupos de 45 aves (quatro grupos para cada sexo) com o objetivo de se acompanhar semanalmente a ingestão de alimento, o peso corporal, ganho de peso e teor de nitrogênio na carcaça através de abates semanais durante o período de 7 a 56 dias de idade. As dietas experimentais foram formuladas segundo recomendações para a marca comercial (AGROCERES ROSS, 1997), atendendo as necessidades nutricionais das aves para cada fase.

Semanalmente os grupos de aves foram pesados para determinação do peso médio vivo, em função deste peso eram selecionadas aves em número representativo para o abate. As aves selecionadas, após jejum de 24 horas, eram abatidas por deslocamento cervical, pesadas, coletada uma amostra de penas, depenadas por completo e então pesadas novamente, por diferença entre o peso da ave em jejum e o peso da ave depenada determinou-se o peso de penas das aves. As carcaças foram congeladas, cortadas com serra e moídas em moinho elétrico para obtenção de amostras homogêneas. Após secas em estufa com ventilação forçada para determinação da matéria seca, as amostras foram novamente moídas e encaminhadas ao laboratório para análises dos teores de nitrogênio $(\mathrm{N})$. As amostras de penas após moídas também foram levadas ao laboratório para análises de N. O teor de nitrogênio das amostras foi determinado utilizando a metodologia de Kjeldahl descrita por SILVA (1990).

Considerando os teores médios de nitrogênio na carcaça e o peso corporal, obtidos semanalmente, foi determinado a exigência de $\mathrm{N}$ líquido para a deposição de um grama de ganho de peso para cada semana, os quais divididos pela eficiência de utilização de nitrogênio da dieta forneceu a exigência de nitrogênio bruto para ganho de peso. As exigências para ganho de peso foram determinadas para as três fases de criação, 7 a 21, 22 a 42 e 43 a 56 dias, de acordo com os aspectos fisiológicos do crescimento de frangos de corte.
A eficiência de utilização do nitrogênio da dieta foi determinada como sendo o coeficiente de regressão da equação do nitrogênio retido em função do nitrogênio ingerido estabelecido em um ensaio realizado com frangos de corte pela técnica do abate comparativo.

Os modelos de análises de regressões, seus coeficientes de determinação e sua significância foram obtidos por intermédio do programa estatístico STATISTICA (1996).

\section{Elaboração das equações}

Considerando as exigências de mantença e ganho de peso determinadas, foram elaboradas equações de predição das exigências diárias de proteína bruta $(\mathrm{N}$ $x$ 6,25) para frangos de corte machos e fêmeas de 7 a 21,22 a 42 e 43 a 56 dias de idade.

Avaliação das equações

Para a avaliação das equações elaboradas foi conduzido um ensaio experimental em temperatura ambiente, utilizando 360 frangos de corte de um dia de idade. As aves foram distribuídas em quatro grupos de 45 aves para cada sexo, onde semanalmente foram quantificados o ganho de peso vivo, consumo alimentar e a proteína ingerida. A retenção corporal de proteína foi determinada por abates e quantificações do teor protéico corporal.

Os dados obtidos foram aplicados nas equações para determinar a exigência de proteína bruta das aves. O consumo de proteína predito pelas equações elaboradas foram comparados com o preconizado em equação descrita na literatura (SCOTT et al., 1982) e com o consumo de proteína quantificado no ensaio.

\section{Resultados e Discussão}

\section{Exigências de proteína para mantença}

Os dados obtidos no ensaio de balanço de nitrogênio são apresentados na Tabela 2.

O nível de $\mathrm{PB}$ da ração promoveu alterações no peso das aves, onde dietas com níveis abaixo de $10 \%$ de PB provocaram redução no ganho de peso. $\mathrm{O}$ balanço de nitrogênio $\left(\mathrm{g} / \mathrm{kg}^{0,75} / \mathrm{dia}\right)$ foi reduzido proporcionalmente ao teor de $\mathrm{PB}$ da ração para ambos os sexos.

As regressões do balanço de nitrogênio em função da ingestão do mesmo, forneceram as estimativas das exigências de $\mathrm{N}$ para mantença e os valores das perdas endógenas e metabólicas para frangos 
machos e fêmeas (Tabela 3 ). As equações de regressão obtidas forneceram as estimativas de nitrogênio para mantença $\left(\mathrm{Nm}, \mathrm{mg} / \mathrm{kg}^{0,75} / \mathrm{dia}\right)$ como sendo o valor do nitrogênio ingerido (NI) quando a ave está em balanço de nitrogênio igual a zero, ou seja, não está depositando nem excretando nitrogênio. As exigências de Nm multiplicadas por 6,25 forneceram as estimativas das exigências em proteína bruta para mantença (PBm, mg/kg0,75/dia). Considerando NI nulo, estimou-se as perdas de nitrogênio endógena e metabólica (PNend).
Na Tabela 3 pode-se verificar maiores exigências de $\mathrm{N}$ para mantença e perdas endógenas para frangos de corte fêmeas em relação aos machos, evidenciando a diferença no metabolismo protéico entremachos e fêmeas.

Os valores determinados no presente trabalho para a exigência de $\mathrm{Nm}$ em frangos de corte machos de $212 \mathrm{mg}$ de N/kg $/ \mathrm{kg}^{0,75} /$ dia e fêmeas de $280 \mathrm{mg}$ de N/

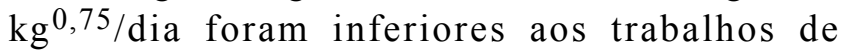
HURWITZ et al. (1978), que encontraram valores de $370 \mathrm{mg}$ de $\mathrm{N} / \mathrm{kg}^{0,67} / \mathrm{dia}$, de SCOTT et al. (1982) com $420 \mathrm{mg}$ de $\mathrm{N} / \mathrm{kg}^{0,75} /$ dia para aves em cresci-

Tabela 2 - Médias para variação no peso corporal, ingestão, excreção e balanço de nitrogênio durante quatro dias de coleta de excretas de frangos de corte machos e fêmeas da marca comercial Ross

Table 2 - Means of body weight gain, nitrogen intake, excretion and balance for four days feces collect of males and females Ross broilers

Níveis de proteína bruta

Crude protein levels

\begin{tabular}{|c|c|c|c|c|}
\hline & & & & \\
\hline & $16 \%$ & $10 \%$ & $6 \%$ & $3 \%$ \\
\hline \multicolumn{5}{|l|}{ Machos } \\
\hline Males & & & & \\
\hline Variação de peso (g) & $238 \pm 95,2$ & $241 \pm 43,9$ & $132 \pm 34,1$ & $55 \pm 16,7$ \\
\hline Weight gain $(g)$ & & & & \\
\hline Nitrogênio ingerido $\left(\mathrm{g} / \mathrm{kg}^{0,75} / \mathrm{dia}\right)$ & $1,72 \pm 0,24$ & $1,32 \pm 0,09$ & $0,85 \pm 0,07$ & $0,32 \pm 0,01$ \\
\hline $\begin{array}{l}\text { Nitrogênio excretado }\left(\mathrm{g} / \mathrm{kg}^{0,75} / \mathrm{dia}\right) \\
\text { Nitrogen excretion }\left(\mathrm{g} / \mathrm{kg}^{0.75} / \text { dav }\right)\end{array}$ & $0,80 \pm 0,08$ & $0,51 \pm 0,03$ & $0,33 \pm 0,03$ & $0,23 \pm 0,02$ \\
\hline $\begin{array}{l}\text { Balanço de nitrogênio }\left(\mathrm{g} / \mathrm{kg}^{0}, 75 / \mathrm{dia}\right) \\
\text { Nitrogen balance }\left(\mathrm{g} / \mathrm{kg}^{0.75} / \text { day }\right)\end{array}$ & $0,92 \pm 0,20$ & $0,81 \pm 0,06$ & $0,52 \pm 0,06$ & $0,09 \pm 0,03$ \\
\hline \multicolumn{5}{|l|}{ Fêmeas } \\
\hline Females & & & & \\
\hline $\begin{array}{l}\text { Variação de peso }(\mathrm{g}) \\
\text { Weight }\end{array}$ & $248 \pm 26,5$ & $218 \pm 14,9$ & $156 \pm 31,5$ & $47 \pm 24,3$ \\
\hline $\begin{array}{l}\text { Weight gain }(\mathrm{g}) \\
\text { Nitrogênio ingerido }\left(\mathrm{g} / \mathrm{kg}^{0,75} / \mathrm{dia}\right) \\
\text { Nitrogen intake }\left(\mathrm{g} / \mathrm{kg}^{0.75} / \text { day }\right)\end{array}$ & $1,98 \pm 0,14$ & $1,35 \pm 0,07$ & $0,90 \pm 0,06$ & $0,32 \pm 0,03$ \\
\hline $\begin{array}{l}\text { Nitrogênio excretado }\left(\mathrm{g} / \mathrm{kg}^{0,75} / \mathrm{dia}\right) \\
\text { Nitrogen excretion }\left(\mathrm{g} / \mathrm{kg}^{0.75} / \text { day }\right)\end{array}$ & $1,01 \pm 0,15$ & $0,64 \pm 0,12$ & $0,42 \pm 0,04$ & $0,29 \pm 0,03$ \\
\hline $\begin{array}{l}\text { Balanço de nitrogênio }\left(\mathrm{g} / \mathrm{kg}^{0,75} / \mathrm{dia}\right) \\
\text { Nitrogen balance }\left(\mathrm{g} / \mathrm{kg}^{0.75} / \text { day }\right)\end{array}$ & $0,97 \pm 0,08$ & $0,71 \pm 0,06$ & $0,48 \pm 0,05$ & $0,04 \pm 0,05$ \\
\hline
\end{tabular}

Tabela 3 - Regressão do balanço de nitrogênio na ingestão de nitrogênio, estimativas das exigências de nitrogênio e proteína bruta para mantença ( $\mathrm{Nm}$ e $\mathrm{PBm}$, respectivamente) e as perdas de nitrogênio endógenas e metabólicas (PNend) de frangos de corte machos e fêmeas

Table 3 - Regression of nitrogen balance on nitrogen intake, nitrogen and protein requirements estimates for maintenance ( $\mathrm{Nm}$ and $\mathrm{CPm}$, respectively) and endogenous metabolic losses (Lnend) of nitrogen for males and females broilers

\begin{tabular}{|c|c|c|c|c|}
\hline Equação * & $\mathrm{r}^{2}$ & $\mathrm{Nm}(\mathrm{Nm})$ & $\mathrm{PBm}(\mathrm{CPm})$ & PNend(Lnend) \\
\hline Equation * & & & $\left(\mathrm{mg} / \mathrm{kg}^{0,75} / \mathrm{dia}\right) \quad\left(\mathrm{mg} / \mathrm{kg}^{0.75} /\right.$ day $)$ & \\
\hline $\begin{array}{l}\text { Machos } \\
\text { Males }\end{array}$ & & & & \\
\hline $\begin{array}{l}\mathrm{BN}=-0,1722 \cdot \mathrm{NI}^{2}+0,9737 . \mathrm{NI}-0,1983 \\
\text { Fêmeas }\end{array}$ & 0,97 & 212 & 1323 & 198 \\
\hline $\begin{array}{l}\text { Females } \\
\mathrm{BN}=-0,1803 \cdot \mathrm{NI}^{2}+0,9722 \cdot \mathrm{NI}-0,2578\end{array}$ & 0,97 & 280 & 1748 & 258 \\
\hline
\end{tabular}


mento, e de MACLEOD (1990) que determinou a exigência de nitrogênio para mantença de fêmeas de frango de corte como sendo entre 900 e $1100 \mathrm{mg}$ de $\mathrm{N} / \mathrm{kg}^{0,75} /$ dia.

Recentemente, em outras teses desenvolvidas na FCAV - UNESP - Jaboticabal, utilizando a mesma metodologia do presente trabalho, foram determinadas as exigências de $\mathrm{N}$ para mantença de matrizes em crescimento de $323 \mathrm{mg} / \mathrm{kg}^{0,75} / \mathrm{dia}$ (SILVA, 1999), para poedeiras em produção de $307 \mathrm{mg} / \mathrm{kg}^{0,75} / \mathrm{dia}$ (BASAGLIA, 1999) e para matrizes em produção de $365 \mathrm{mg} / \mathrm{kg}^{0,75} / \mathrm{dia}$ (RABELLO, 2001). Relacionando esses resultados aos encontrados no presente trabalho, pode-se observar maior proximidade dos valores, mesmo em espécies diferentes, com relação aos valores encontrados na literatura, evidenciando a necessidade de padronização de metodologia para melhores comparações.

Segundo SCOTT et al. (1982), a proteína endógena do trato digestivo é constituída de saliva, suco gástrico, suco pancreático, descamação das células epiteliais da mucosa intestinal e mucinas que são produzidas e secretadas pelas células ao longo do trato gastrintestinal. Esta proteína endógena aumenta a quantidade de proteína total que passa pelo trato digestivo. Os autores citam que a perda diária de nitrogênio endógeno é de aproximadamente $250 \mathrm{mg}$ de nitrogênio/kg de peso corporal.

BOORMAN (1981) sugeriu que as perdas de nitrogênio endógeno são comparadas com a proporção da proteína da dieta que é utilizada para mantença, sendo que, para aves, esta porcentagem é, aproxima-

Tabela 4 - Nitrogênio líquido retido na carcaça para cada grama de ganho de peso corporal $(\mathrm{mg} / \mathrm{g})$ nas diferentes idades dos frangos de corte Ross machos e fêmeas

Table 4 - Net nitrogen on carcass for each gram of weight gain $(\mathrm{mg} / \mathrm{g})$ in males and females Ross broilers at different ages

\begin{tabular}{ccc}
\hline & \multicolumn{2}{c}{$\begin{array}{c}\text { N líquido }(\mathrm{mg} / \mathrm{g} \text { de peso corporal) } \\
\text { Net nitrogen }(\mathrm{mg} / \mathrm{g} \text { weight } \text { gain })\end{array}$} \\
\cline { 2 - 3 } Idade (dias) & Machos & Fêmeas \\
Age (days) & Males & Females \\
\hline 7 & 28,5 & 28,8 \\
14 & 28,6 & 29,9 \\
21 & 31,3 & 30,5 \\
28 & 31,3 & 31,0 \\
35 & 33,7 & 32,7 \\
42 & 31,2 & 31,9 \\
49 & 32,8 & 34,5 \\
56 & 33,9 & 37,1 \\
\hline
\end{tabular}

damente, $10 \%$. Os valores de perdas de nitrogênio endógeno encontrados no trabalho foram de 198 e $258 \mathrm{mg} / \mathrm{kg}^{0,75} /$ dia, para machos e fêmeas, respectivamente, correspondendo a uma proporção de aproximadamente $15 \%$ da proteína necessária para mantença.

Exigências de proteína para o ganho de peso

A exigência de nitrogênio líquido para ganho de peso foi determinada como o teor de nitrogênio líquido retido na carcaça dos frangos por grama de peso corporal (Tabela 4).

A eficiência de utilização do nitrogênio do presente trabalho foi determinada em um ensaio experimental pelo método do abate comparativo, como sendo o coeficiente de regressão linear do teor de $\mathrm{N}$ retido na carcaça em função do $\mathrm{N}$ ingerido (Nretido $=-0,43+0,72$. N ingerido). Considerando os valores médios de nitrogênio líquido por grama de peso corporal (Tabela 4) nas diferentes fases de criação (7 a 21, 22 a 42 e 43 a 56 dias de idade) e a eficiência de utilização do $\mathrm{N}(0,72)$, foram determinadas as exigências de nitrogênio diária para ganho(NLgp, $\mathrm{mg} / \mathrm{g}$ ) e os valores das exigências em proteína bruta $(\mathrm{N}$ x 6,25) para ganho de peso (PBgp) (Tabela 5).

Verificou-se aumento na exigência de nitrogênio líquido, bem como na exigência de proteína para ganho (mg/g), com a idade das aves, sendo mais evidente nas fêmeas. Isto pode ser explicado pelos pequenos aumentos na deposição de $\mathrm{N}$ corporal, com o avanço da idade das aves (Tabela 4). Segundo SCOTT et al. (1982), fatores como genótipo e idade afetam as exigências de proteína para mantença e para o crescimento, sendo que as exigências para o

Tabela 5 - Exigências de nitrogêniolíquido(NLgp), nitrogênio bruto (Ngp) e de proteína (PBgp) para o ganho de peso de frangos de corte machos e fêmeas da marca comercial Ross para cada fase de criação

Table 5 - Net nitrogen (NLgp), crude nitrogen (Ngp) and protein (PBgp) requirements for weight gain males and females Ross broilers at each phase

\begin{tabular}{lccc}
\hline $\begin{array}{l}\text { Idade (dias) } \\
\text { Age (days) }\end{array}$ & $\begin{array}{c}\text { NLgp } \\
(\mathrm{mg} / \mathrm{g})\end{array}$ & $\begin{array}{c}\text { Ngp* } \\
(\mathrm{mg} / \mathrm{g})\end{array}$ & $\begin{array}{c}\text { PBgp } \\
(\mathrm{mg} / \mathrm{g})\end{array}$ \\
\hline & \multicolumn{3}{c}{$\begin{array}{c}\text { Machos } \\
\text { Males }\end{array}$} \\
7 a 21 & 40,93 & 255,8 \\
22 a 42 & 29,47 & 44,28 & 276,7 \\
43 a 56 & 31,88 & 45,32 & 283,3 \\
& 32,63 & Fêmeas & \\
7 a 21 & & Females & \\
22 a 42 & & 41,29 & 258,1 \\
43 a 56 & 29,73 & 43,79 & 273,7 \\
\hline
\end{tabular}

${ }^{*} \mathrm{Ngp}=\mathrm{NLgp} / 0,72$ 
crescimento são diretamente relacionadas com os teores do nutriente no corpo e as taxas de deposição. As diferenças encontradas nas exigências para ganho de peso em função da idade da ave e sexo, evidenciam a importância de diferentes programas alimentares para machos e fêmeas, além da divisão do programa alimentar em diferentes fases, de acordo com os aspectos fisiológicos das aves.

Os valores de exigência de proteína para ganho de peso de frangos de corte determinados no presente trabalho foram próximos aos valores encontrados por SCOTT et al. (1982) de $295 \mathrm{mg} / \mathrm{g}$ de ganho e inferiores aos valores das exigências para frangas de postura em crescimento de 350 a $625 \mathrm{mg} / \mathrm{g}$ e 406 a $563 \mathrm{mg} / \mathrm{g}$ determinados por ALBINO et al. (1995) e BASAGLIA (1996), respectivamente.

Os valores de eficiência para deposição de nitrogênio corporal encontrados na literatura são muito variáveis, SCOTT et al. (1982) preconizaram uma eficiência de $61 \%$ para aves em geral. MACLEOD (1990) trabalhando com frangos de corte encontrou $46 \%$ de eficiência de retenção de nitrogênio, valor inferior ao encontrado no presente trabalho (72\%). Em função do maior valor encontrado neste trabalho para eficiência de deposição de nitrogênio, pode-se justificar os menores valores de exigência de nitrogênio bruto para ganho, uma vez que esse valor é determinado a partir da exigência de nitrogênio líquido dividido pela eficiência.

Equações de predição das exigências de proteína bruta

A partir dos valores das exigências para mantença (Tabela 3) e ganho de peso (Tabela 5) foram elaboradas equações de predição para as exigências diárias de proteína para frangos de corte. As equações apresentadas levam em consideração o peso corporal das aves e o ganho de peso diário.
7 a 21 dias: - machos: $\mathrm{PB}=1,323 \mathrm{xP}^{0,75}+0,256 \mathrm{xG}$

- fêmeas: $\mathrm{PB}=1,748 \times \mathrm{P}^{0,75}+0,258 \mathrm{xG}$

22 a 42 dias: - machos: $\mathrm{PB}=1,323 \mathrm{xP}^{0,75}+0,277 \times \mathrm{xG}$

- fêmeas: $\mathrm{PB}=1,748 \times \mathrm{P}^{0,75}+0,274 \mathrm{xG}$

43 a 56 dias: - machos: $\mathrm{PB}=1,323 \times \mathrm{P}^{0,75}+0,283 \times \mathrm{x}$

- fêmeas: $\mathrm{PB}=1,748 \mathrm{xP}^{0,75}+0,300 \mathrm{xG}$

em que: $\mathrm{PB}=$ exigência diária de proteína bruta $(\mathrm{g} /$ ave/dia); $\mathrm{P}=$ peso corporal em $\mathrm{kg} ; \mathrm{G}=$ ganho de peso diário em g por dia.

Avaliação das equações de predição das exigências de proteína bruta

As equações determinadas no presente estudo foram avaliadas em um estudo de simulação aplicando nas equações elaboradas os dados de peso vivo médio e ganho de peso semanais obtidos no ensaio experimental (Tabela 6).

Nas Tabelas 7 e 8 são apresentadas as diferenças entre os consumos de PB observados no ensaio experimental e os determinados pelas equações e a soma dos quadrados das diferenças (SQd) para machos e fêmeas, respectivamente.

Observando as Tabelas 7 e 8, verifica-se que as equações elaboradas subestimaram o consumo de PB no período total para frangos de corte em 242 e $225 \mathrm{~g}$, para machos e fêmeas, respectivamente, em relação ao consumo de $\mathrm{PB}$ observado no ensaio experimental. Essa diferença no consumo de PB estimado pela equação e observado no ensaio é explicada devido ao fornecimento ad libitum da dieta com altos níveis de PB $(21,5 \%$ de 7 a $21,19,0 \%$ de 22 a 42 e $17,5 \%$ de 43 a 56 dias de idade) que geralmente são recomendados para atender as exigências dos aminoácidos e não para as exigências específicas de PB.

\begin{tabular}{|c|c|c|c|c|}
\hline \multirow[t]{2}{*}{$\begin{array}{l}\text { Idade (dias) } \\
\text { Age (days) }\end{array}$} & \multicolumn{2}{|c|}{$\begin{array}{l}\text { Peso vivo }(\mathrm{g}) \\
\text { Live weight }(\mathrm{g})\end{array}$} & \multicolumn{2}{|c|}{$\begin{array}{c}\text { Ganho de peso (g/dia) } \\
\text { Weight gain (g/day) }\end{array}$} \\
\hline & $\begin{array}{l}\text { Machos } \\
\text { Males }\end{array}$ & $\begin{array}{l}\text { Fêmeas } \\
\text { Females }\end{array}$ & $\begin{array}{l}\text { Machos } \\
\text { Males }\end{array}$ & $\begin{array}{l}\text { Fêmeas } \\
\text { Females }\end{array}$ \\
\hline 7 a 14 & 270 & 250 & 34,60 & 31,95 \\
\hline 15 a 21 & 580 & 540 & 55,40 & 50,72 \\
\hline 22 a 28 & 1030 & 930 & 73,88 & 61,97 \\
\hline 29 a 35 & 1580 & 1380 & 81,89 & 65,96 \\
\hline 36 a 42 & 2180 & 1850 & 89,14 & 66,54 \\
\hline 43 a 49 & 2770 & 2290 & 80,54 & 61,89 \\
\hline 50 a 56 & 3350 & 2720 & 84,71 & 59,75 \\
\hline
\end{tabular}


As exigências de PB fracionadas para mantença e ganho de peso corresponderam respectivamente a 8,6 e $91,4 \%$ para machos (Tabela 7 ) e 12,1 e $87,9 \%$ para fêmeas (Tabela 8) da exigência total de PB. Esses valores demonstraram a maior exigência em PB para ganho de peso das aves devido ao fato de as mesmas estarem em crescimento. A proporção encontrada destinada para mantença foi inferior ao proposto por HURWITZ e BORNSTEIN (1973) de
25 a $30 \%$ das exigências totais. Entretanto, BOORMAN (1981) definiu que a porcentagem da proteína da dieta utilizada para mantença nas aves é aproximadamente $10 \%$.

Os valores de soma de quadrado das diferenças (SQd) demonstram que as equações elaboradas para fêmeas se ajustaram melhor ao consumo de PB observado no ensaio, em relação aos machos.

Na Tabela 9 são apresentados os dados de con-

Tabela 7 - Consumo de proteína bruta total (PBtotal), proteína para mantença (PBm) e ganho de peso (PBgp) determinados pelas equações de predição e consumo de proteína bruta observado no ensaio (PBobs) para frangos de corte Ross machos de 7 a 56 dias de idade

Table 7 - Crude protein intake (PBtotal), protein for maintenance (PBm) and weight gain (PBgp) determined by prediction equations and crude protein intake showed on trial (PBobs) for males Ross broilers at 7 to 56 days of age

\begin{tabular}{|c|c|c|c|c|c|}
\hline \multirow[t]{2}{*}{$\begin{array}{l}\text { Idade (dias) } \\
\text { Age (days) }\end{array}$} & \multicolumn{3}{|c|}{$\begin{array}{l}\text { Equação }^{1} \text { (g/ave/dia) } \\
\text { Equation }^{1}(\mathrm{~g} / \text { bird/day })\end{array}$} & \multirow[t]{2}{*}{$\begin{array}{l}\text { PBobs (g/ave/dia) } \\
\text { PBobs (g/bird/day) }\end{array}$} & \multirow[t]{2}{*}{$\begin{array}{l}\text { Diferenças } \\
\text { Differences }\end{array}$} \\
\hline & $\mathrm{PBm}$ & PBgp & PBtotal & & \\
\hline 7 a 14 & 0,48 & 8,86 & 9,34 & 11,67 & $-2,33$ \\
\hline 15 a 21 & 0,87 & 14,18 & 15,05 & 20,08 & $-5,03$ \\
\hline 22 a 28 & 1,35 & 20,47 & 21,81 & 21,80 & 0,01 \\
\hline 29 a 35 & 1,86 & 22,68 & 24,54 & 28,05 & $-3,51$ \\
\hline 36 a 42 & 2,37 & 24,69 & 27,06 & 31,89 & $-4,83$ \\
\hline 43 a 49 & 2,84 & 22,79 & 25,63 & 34,33 & $-8,70$ \\
\hline 50 a 56 & 3,27 & 23,97 & 27,25 & 37,50 & $-10,25$ \\
\hline Total 4 & $91(8,6 \%)$ & $964(91,4 \%)$ & 1055 & 1297 & $247^{3}$ \\
\hline
\end{tabular}

${ }^{1}$ Equação (Equation): 7 a 21 dias (days): - $\mathrm{PB}$ (g/ave/dia) (CP, g/bird/day)=1,323xP0,75 + 0,256xG; 22 a 42 dias (days): - PB(g/ave/ dia) $\left(C P, g /\right.$ bird/day) $=1,323 \times P^{0,75}+0,277 \times G ; 43$ a 56 dias (days): $-P B(g / a v e / d i a)(C P, g /$ bird/day $)=1,323 \times P^{0,75}+0,283 \times G$

2 Diferenças (Differences) $=$ consumo de PB determinado pela equação (CPintake determined by equation) - consumo de PB observado em ensaio experimental (CP intake showed on trial).

3 Soma de quadrado das diferenças (Sum of squares of diferences).

4 Totais das exigências de PB de 7 a 56 dias (g/ave) $=\sum$ [exigências semanais de PB (g/ave/dia) $\times 7$ (dias)] (Total CP requirements from 7 to 56 days ( $/$ /bird) $=\sum$ [weekly requirements of CP (g/bird/day) $\times 7$ (days)]).

Tabela 8 - Consumo de proteína bruta total (PBtotal), proteína para mantença (PBm) e ganho de peso (PBgp) determinados pelas equações de predição e consumo de proteína bruta observado no ensaio (PBobs) para frangos de corte Ross fêmeas de 7 a 56 dias de idade

Table 8 - Crude protein intake (PBtotal), protein for maintenance (PBm) and weight gain (PBgp) determined by prediction equations and crude protein intake showed on trial (PBobs) for females Ross broilers at 7 to 56 days of age

\begin{tabular}{|c|c|c|c|c|c|}
\hline \multirow[t]{2}{*}{$\begin{array}{l}\text { Idade (dias) } \\
\text { Age (days) }\end{array}$} & \multicolumn{3}{|c|}{$\begin{array}{l}\text { Equação }^{1} \text { (g/ave/dia) } \\
\text { Equation }^{1} \text { (g/bird/day) }\end{array}$} & \multirow[t]{2}{*}{$\begin{array}{l}\text { PBobs (g/ave/dia) } \\
\text { PBobs (g/bird/day) }\end{array}$} & \multirow[t]{2}{*}{$\begin{array}{l}\text { Diferenças }^{2} \\
\text { Differences }^{2}\end{array}$} \\
\hline & $\mathrm{PBm}$ & PBgp & PBtotal & & \\
\hline 7 a 14 & 0,61 & 8,24 & 8,85 & 9,83 & $-0,98$ \\
\hline 15 a 21 & 1,09 & 13,09 & 14,17 & 18,42 & $-4,25$ \\
\hline 22 a 28 & 1,65 & 16,98 & 18,63 & 19,33 & $-0,70$ \\
\hline 29 a 35 & 2,22 & 18,07 & 20,30 & 23,93 & $-3,64$ \\
\hline 36 a 42 & 2,76 & 18,23 & 20,99 & 26,95 & $-5,96$ \\
\hline 43 a 49 & 3,26 & 18,57 & 21,82 & 28,71 & $-6,88$ \\
\hline 50 a 56 & 3,70 & 17,93 & 21,63 & 31,38 & $-9,76$ \\
\hline Total 4 & $107(12,1 \%)$ & $778(87,9 \%)$ & 885 & 1110 & $211^{3}$ \\
\hline
\end{tabular}

${ }^{1}$ Equação (Equation): 7 a 21 dias (days): - $\mathrm{PB}$ (g/ave/dia) (CP, g/bird/day)=1,748xP0,75 + 0,258xG; 22 a 42 dias (days): - PB(g/ave/ dia) $\left(C P\right.$, g/bird/day) $=1,748 \times P^{0,75}+0,274 \times G ; 43$ a 56 dias (days): $-\mathrm{PB}\left(\mathrm{g} /\right.$ ave/dia) $\left(C P\right.$, g/bird/day) $=1,748 \times P^{0,75}+0,300 \times G$.

2 Diferenças (Diferences) $=$ consumo de PB determinado pela equação (CP intake determined by equation) - consumo de PB observado em ensaio experimental (CP intake showed on trial).

${ }^{3}$ Soma de quadrado das diferenças (Sum of squares of diferences).

${ }^{4}$ Totais das exigências de PB de 7 a 56 dias (g/ave) $=\sum$ [exigências semanais de PB (g/ave/dia) x 7 (dias)] (Total CP requirements from 7 to 56 days (g/bird) $=\sum$ [weekly requirements of CP (g/bird/day) $\times 7$ (days)]). 
sumo em PB determinados com a aplicação dos dados de desempenho (Tabela 6) na equação elaborada por SCOTT et al. (1982).

Pode-se observar que a equação de SCOTT et al. (1982) promoveu boa predição das exigências de PB total consideradas para frangos machos (1282 g/ave) e fêmeas (1033 g/ave), apresentando valores baixos de soma de quadrado das diferenças (32 para machos e 62 para fêmeas) comparando com o consumo de PB observado em ensaio para machos e fêmeas (Tabelas 7 e 8 , respectivamente).

Verificaram-se menores valores de exigência em PB estimados nas equações determinadas no presente trabalho em relação aos valores estimados pela equação de SCOTT et al. (1982).

As diferenças entre a equação de SCOTT et al. (1982) e as equações avaliadas são maiores para a exigência de $\mathrm{PB}$ destinada à mantença. Conforme a equação de SCOTT et al. (1982) a exigência para mantença é cerca de $17 \%$ da exigência total, ao passo que a equação do presente trabalho determinou valores para macho de $9 \%$ e para fêmea de $12 \%$ (Tabelas 7 e 8 , respectivamente). As exigências de PB para o crescimento de acordo com as equações foram para machos de $91 \%$ e para fêmeas de $88 \%$, sendo superior ao valor de $83 \%$ determinado pela equação de SCOTT et al. (1982).

Para dedução do modelo de SCOTT et al. (1982), os autores consideraram uma eficiência de utilização da PB da dieta de $61 \%$, e para os teores de PB do tecido corporal, das penas e das perdas endógenas, os valores de $18 \%, 82 \%$ e $1600 \mathrm{mg}$ de $\mathrm{PB} / \mathrm{kg}$ de peso corporal/dia, respectivamente.

As diferenças nas equações elaboradas no presente trabalho e de SCOTT et al. (1982) são explicadas em grande parte pelas diferenças entre as eficiências de utilização da proteína bruta da dieta, sendo utilizado um valor de $72 \%$ de eficiência no presente trabalho. Um ponto conflitante na determinação de exigências nitrogenadas e protéicas é o estabelecimento da eficiência de utilização do nitrogênio da dieta, o qual depende do balanço de aminoácidos e do fornecimento de energia (EMMANS, 1995).

Além da diferença nas eficiências de utilização da proteína considerada nos trabalhos, pode-se destacar ainda o fracionamento da exigência de proteína para o ganho de peso e mantença, demonstrando que os frangos de corte de marcas comerciais atuais utilizam mais proteína, cerca de $90 \%$ da exigência total, para o ganho de peso em relação a marcas comerciais de frangos de corte utilizadas por SCOTT et al. (1982), cerca de 83\%, provavelmente um resultado da evolução genética para maior deposição de tecido protéico em frangos de corte.

MARTIN et al. (1994) sugeriram que é necessário considerar separadamente a exigência de proteína para mantença, para crescimento de tecido e crescimento de penas e que a exigência para mantença deve levar em consideração a manutenção de proteína corporal e a manutenção da proteína das

Tabela 9 - Consumo de proteína bruta total (PBtotal), proteína para mantença (PBm) e ganho de peso (PBgp) determinados pela equação de SCOTT et al. (1982) para frangos de corte Ross machos e fêmeas de 7 a 56 dias de idade

Table 9 - Crude protein intake (PBtotal), protein for maintenance (PBm) and weight gain (PBgp) determined by the prediction equation of SCOTT et al. (1982) for males and females Ross broilers at 7 to 56 days of age

\begin{tabular}{|c|c|c|c|c|c|c|c|c|}
\hline \multirow[t]{2}{*}{$\begin{array}{l}\text { Idade (dias) } \\
\text { Age (days) }\end{array}$} & \multicolumn{4}{|c|}{$\begin{array}{l}\text { Machos } \\
\text { Males }\end{array}$} & \multicolumn{4}{|c|}{$\begin{array}{l}\text { Fêmeas } \\
\text { Females }\end{array}$} \\
\hline & $\mathrm{PBm}$ & PBgp & PBtotal & Dif. $^{2}$ & $\mathrm{PBm}$ & PBgp & PBtotal & Dif. $^{2}$ \\
\hline 7 a 14 & 0,70 & 10,54 & 11,23 & $-0,44$ & 0,65 & 9,73 & 10,38 & 0,55 \\
\hline 15 a 21 & 1,52 & 16,87 & 18,39 & $-1,69$ & 1,41 & 15,44 & 16,86 & $-1,56$ \\
\hline 22 a 28 & 2,71 & 22,50 & 25,21 & 3,41 & 2,45 & 18,87 & 21,32 & 1,99 \\
\hline 29 a 35 & 4,14 & 24,94 & 29,07 & 1,02 & 3,62 & 20,09 & 23,71 & $-0,22$ \\
\hline 36 a 42 & 5,71 & 27,14 & 32,85 & 0,96 & 4,84 & 20,26 & 25,10 & $-1,86$ \\
\hline 43 a 49 & 7,27 & 24,52 & 31,79 & $-2,54$ & 6,02 & 18,85 & 24,86 & $-3,84$ \\
\hline 50 a 56 & 8,78 & 25,79 & 34,58 & $-2,92$ & 7,13 & 18,19 & 25,33 & $-6,06$ \\
\hline Total 4 & $216(16,8 \%)$ & $1066(83,2 \%)$ & 1282 & $32^{3}$ & $183(17,7 \%)$ & $850(82,3 \%)$ & 1033 & $62^{3}$ \\
\hline
\end{tabular}

1 SCOTT et al. (1982): $\mathrm{PB}(\mathrm{g} / \mathrm{ave} / \mathrm{dia})(\mathrm{CP}, \mathrm{g} / \mathrm{bird} /$ day $)=((0,18 \times \mathrm{g}) / 0,61)+((0,0016 \times \mathrm{P}) / 0,61)+((0,07 \times 0,082 \times \mathrm{G}) / 0,61)$, $\mathrm{P}$ em gramas

2 Diferenças (Differences) = consumo de PB determinado pela equação de SCOTT et al. (1982) (CP intake determined by the equation of SCOTT et al. (1982)) - consumo de PB observado em ensaio experimental apresentados nas Tabelas 7 e 8, para machos e fêmeas, respectivamente (CP intake showed on trial present on Tables 7 and 8, for males and females respectively).

3 Soma de quadrado das diferenças (Sum of squares of diferences).

4 Totais das exigências de PB de 7 a 56 dias (g/ave) $=\sum$ [exigências semanais de PB (g/ave/dia) x 7 (dias)] (Total CP requirements form 7 to 56 days $(\mathrm{g} / \mathrm{bird})=\sum$ [weekly requirements of $\mathrm{CP}$ (g/bird/day) $\times 7$ (days)] ). 
penas. Esses resultados destacam a importância e a necessidade de considerar separadamente as exigências de manutenção e crescimento de tecido protéico e penas.

Os manuais de criação das linhagens de frangos de corte preconizam maiores valores para as exigências em PB, visando o atendimento também das exigências em aminoácidos. As equações determinadas visam o atendimento das exigências mínimas de $\mathrm{PB}$, sendo necessário para sua aplicação prática de maior atenção, afim de evitar deficiências em função das exigências mínimas em aminoácidos.

A proposta de níveis reduzidos de PB das dietas com suplementação de aminoácidos sintéticos visam a maximização da eficiência de utilização da proteína e do aproveitamento dos aminoácidos para a síntese protéica, reduzindo principalmente os efeitos negativos do excesso de nitrogênio e aminoácidos.

Segundo PARSONS e BAKER (1994), o ideal para frangos de corte é o fornecimento de uma mistura de aminoácidos ou proteínas com máxima disponibilidade na digestão e metabolismo, com composição idêntica às exigências para a mantença e crescimento do animal.

\section{Conclusões}

As equações de predição das exigências de proteína bruta desenvolvidas para frangos de corte evidenciaram a necessidade de diferentes programas alimentares em função do sexo e fases de criação das aves.

Os estudos de simulação indicaram que o consumo necessário de proteína predito pelas equações desenvolvidas neste trabalho foi inferior aos consumos de proteína observado no experimento e preconizado pela equação da literatura.

Recomenda-se a utilização das equações elaboradas para a determinação das exigências mínimas de nitrogênio ou proteína bruta, sendo necessário para isto, maior atenção no atendimento das exigências em aminoácidos.

\section{Referências Bibliográficas}

AGROCERES ROSS. 1997. Manual de manejo de frango de corte - AGROSS. Rio Claro, SP. 56p.

ALBINO, L.F.T., BELLAVER, C., FIALHO, F.B. et al. 1995. Estimativas das exigências de energia e proteína para frangas de postura em recria. Pesq. Agropec. Bras., 29(10):1625-1629.

BASAGLIA, R. Exigências de proteina para frangas de postura entre 1 e 18 semanas de idade. Jaboticabal, SP: FCAV, 1999. 91p. Tese (Doutorado em Zootecnia) - Faculdade de Ciências Agrárias e Veterinárias - Universidade Estadual Paulista, 1999.

BASAGLIA, R., SAKOMURA, N.K., ARIKI, J. et al. 1998. Determinação da exigência de nitrogênio para mantença de poedeiras leves. In: CONFERÊNCIA APINCO DE CIÊNCIA E TECNOLOGIA AVÍCOLAS, 1998, Campinas. Anais... Campinas: FACTA, 1998. p.34.

BASAGLIA, R. Exigências de proteina para frangas de postura entre 1 e 18 semanas de idade. Jaboticabal, SP: FCAV, 1996. 91p. Dissertação (Mestrado em Zootecnia) - Faculdade de Ciências Agrárias e Veterinárias - Universidade Estadual Paulista, 1996.

BOORMAN, K.N. 1981. Dietary constraints on nitrogen retention. In: BUTTERY, P.J., LINDSAY, D.B. (Ed.) Protein deposition in animals. London: Butterworths. p.147-166.

BURNHAM, D., GOUS, R.M. 1992 Isoleucine requirements of the chicken: requirement for maintenance. Br. Poult. Sci., 33:59-69.

EMMANS, G.C., 1995. Problems in modelling the growth of poultry. World's Poult. Sci. J., 51:77-89.

HURWITZ, S., SKLAN, D., BARTOV, I. 1978. New formal approaches to determination of energy and amino acid requirements of chickens. Poult. Sci., 57:197-205.

HURWITZ, L., BORNSTEIN, S. 1973. The protein and amino acid requirements of laying hens: suggested models for calculation. Poult. Sci., 52:1124-1134.

LEESON, S., SUMMERS, J.D. 1997. Commercial poultry nutrition. 2.ed. Guelph, Ontario. 355p.

MACLEOD, M.G. 1990. Energy and nitrogen intake, expenditure and retention at $20^{\circ} \mathrm{C}$ in growing fowl given diets with range of energy and protein contents. Brit. J. Nutr., 64:625-637.

MARTIN, P.A., BRADFORD, G., GOUS, R.M., 1994. A formal method of determining the amino acid requirements of laying-type pullets during their growing period. Brit. Poult. Sci., 35:709-724.

NATIONAL RESEARCH COUNCIL - NRC. 1994. Committee on animal nutrition. Subcommittee on poultry nutrition. 9.ed. Washington, D.C. $155 \mathrm{p}$.

PARSONS, C.M., BAKER, D.H. The concept and usage of ideal proteins in the feeding of nonruminantes. In SIMPÓSIO INTERNACIONAL DE PRODUÇÃO DE NÃO-RUMINANTES, 1994, Maringá. Anais... Maringá: EDUEM, 1994. p.119-128.

RABELLO, C.B.V. Equações de predição das exigências de energia e proteína para aves reprodutoras pesadas na fase de produção. Jaboticabal, SP: FCAV, 2001. 121p. Tese (Doutorado em Zootecnia) - Faculdade de Ciências Agrárias e Veterinárias - Universidade Estadual Paulista, 2001.

SANTOMÁ, G. 1991. Necessidades proteicas de las gallinas ponedoras. In: DE BLAS, C., MATEOS, G.G. (Eds.). Nutrition yalimentación de gallinas ponedoras. Madrid: MundiPrensa. p.71-114.

SAKOMURA, N. K. Exigências nutricionais das aves utilizando o modelo fatorial. In: SIMPÓSIO INTERNACIONAL SOBRE EXIGÊNCIAS NUTRICIONAIS DE AVES E SUÍNOS, 1996, Viçosa. Anais... Viçosa: UFV, 1996. p.361-388.

SCOTT, M. L., NESHEIM, M. C., YOUNG, R. 1982. Nutrition of the chicken. 3.ed. Ithaca: M.L. Scott \& Ass. 562p.

SILVA, R. Equações de predição das exigências de energia e proteina para matrizes pesadas na fase de crescimento. Jaboticabal, SP: FCAV, 1999. 130p. Tese (Doutorado em Zootecnia) - Faculdade de Ciências Agrárias e Veterinárias Universidade Estadual Paulista, 1999.

SILVA, D. J. 1990. Análise de alimentos (Métodos químicos e biológicos). 2.ed. Viçosa, MG: UFV. 165p.

STATISTICA. 1996. Version Release 5.1. for windows.

Recebido em: 26/12/00 Aceito em: 10/05/01 